\title{
Role of 3-monthly long-acting injectable paliperidone in the maintenance of schizophrenia
}

This article was published in the following Dove Press journal:

Neuropsychiatric Disease and Treatment

7 November 2017

Number of times this article has been viewed

\section{Claudio Brasso \\ Silvio Bellino \\ Paola Bozzatello \\ Cristiana Montemagni \\ Paola Rocca}

Department of Neurosciences "Rita Levi Montalcini”, University of Turin, Turin, Italy
Correspondence: Paola Rocca

Department of Neurosciences "Rita Levi Montalcini", University of Turin,

Via Cherasco II, I0I26 Turin, Italy

Tel +390116707714

Fax +390111673473

Email paola.rocca@unito.it
Aims: Paliperidone palmitate 3-month (PP3M) represents a new long-acting injectable antipsychotic therapeutic option. This review aims: 1) to summarize available data relating to efficacy, safety, tolerability and costs of PP3M; 2) to describe hospitalization rate, occupational status, treatment preference, satisfaction, adherence and caregiver burden of patients with schizophrenia who participate in PP3M clinical trials; 3) to examine ethical implications, pros and cons of PP3M use and 4) to propose study designs to further assess PP3M.

Methods: On August 21, 2017, a search on PubMed about PPM3, without any filter restriction, was conducted and all available records were analyzed. Records written in a language other than English were excluded.

Results: Twenty-two records were included in this review: 6 reviews, 1 report, 4 pharmacokinetic studies, 2 cost-effectiveness analyses, 1 open-label clinical trial, 2 randomized controlled trials (RCTs), 5 studies based on these 2 RCTs and 1 observational study.

Discussion: According to these last 9 studies, when compared with placebo, PP3M showed a longer time to relapse and good safety and tolerability profiles. Furthermore, when compared with paliperidone palmitate 1 month (PP1M), PP3M treatment showed: 1) non-inferiority in terms of efficacy, safety, tolerability, rate of hospitalization, symptomatic and functional remission, treatment preference and variations of the occupational status; 2) a longer time to relapse after treatment discontinuation and 3) a similar reduction of the caregiver burden.

Conclusion: PP3M is the only 3-monthly long-acting injectable antipsychotic available on the market. This makes it a unique option of treatment, which could be chosen both in early and advanced phases of illness. Nonetheless, longer naturalistic follow-up studies, two-arm head-to-head superiority trials and mirror studies, based on real-world samples of patients, are needed to further assess long-term safety and advantages of this new option of treatment and to define patients' sub-populations that would most beneficiate from it.

Keywords: PP3M, paliperidone palmitate, LAI, antipsychotic, clinical assessment, advantages and disadvantages

\section{Introduction}

Schizophrenia is a pervasive psychotic chronic condition, present in all cultures and historical periods. ${ }^{1}$ It is one of the top 20 causes of disability worldwide: ${ }^{2}$ World Health Organization reported that schizophrenia is responsible for $1.1 \%$ of the total disability-adjusted life years and $2.8 \%$ of the years lived with disability. ${ }^{3}$ It has an important impact on patients' quality of life and mortality, on patients' families and on social and financial costs: ${ }^{1,4,5}$ in developed countries the disorder justifies $1.5 \%-3.0 \%$ of health care expenses. ${ }^{6}$

Schizophrenia has a prevalence estimated at $0.6 \%-0.8 \%$ and its lifetime prevalence is about $1 \%$ worldwide. ${ }^{1}$ Typically, it is preceded by prodromal symptoms leading 
to a first psychotic episode starting in young adulthood. ${ }^{5,7}$ Individuals with schizophrenia have a shorter life expectancy than the general population, an increased risk of physical illness, especially cardiovascular disease, as well as higher rates of suicide and accidental injury. 5,7,8 Episodes of partial or full remission broken by relapses characterize the long-term course of schizophrenia and difficulties in global functioning: ${ }^{5,9}$ most patients are unable to reach at least one milestone, such as being in a stable relationship, having full-time competitive employment or having selfsupported independent living. ${ }^{10}$ Relapse in schizophrenia can be destructive often resulting in hospitalization. ${ }^{11-13}$ In addition, relapse can be strictly connected with a biological risk: it has been hypothesized that active psychosis reflects a period of disease progression to the extent that patients may not come back to their previous level of functioning and can become resistant to treatment. ${ }^{14,15}$ The early phase of schizophrenia, including the first 2 years up to 5 years after the onset, is thought to be essential in determining long-term prognosis. ${ }^{16}$ Therefore, a continued treatment from the early phases of disease may preserve from structural brain changes and progression toward functional deterioration. ${ }^{17-20}$

\section{Poor adherence to treatment and long-acting injectable (LAI) atypical antipsychotics}

Antipsychotic therapy is the mainstay of schizophrenia treatment, and severity and frequency of disease symptoms can be adequately managed by adhering to the prescribed antipsychotic medication. ${ }^{5,21,22}$ The most frequent cause of relapse in schizophrenia is poor adherence to antipsychotic treatment. ${ }^{23,24}$ When patients discontinue their medications, even after the first episode, the risk of symptomatic relapse increases dramatically. ${ }^{25}$ In clinical settings, poor compliance is common, especially in the early stages of the disease, ${ }^{26-29}$ with between $40 \%$ and $60 \%$ of patients with schizophrenia partially or totally noncompliant with oral antipsychotics. ${ }^{30,31}$ It has been highlighted that up to $74 \%$ of people affected by schizophrenia started to discontinue their medications after 18 months and that up to $42 \%$ of patients stopped their therapy within 1 year after the first psychotic episode. ${ }^{32,33}$ Studies using more strict measurement methodology, such as pill count, electronic monitoring and blood drug level, often indicate higher levels of non-adherence. ${ }^{34-37}$ Moreover, the duration of follow-up certainly has a clear influence on the observed frequencies of non-adherence. Therefore, it is reasonable to consider that adherence is much lower in routine care than in clinical trials. ${ }^{38}$ Poor adherence has serious repercussions on the course of the disease in terms of relapses..$^{39,40}$ Once illness recurrence occurs, the severity of symptoms rapidly returns to levels similar to the initial psychotic episode. ${ }^{25}$ This leads to important consequences: inability to work and hospitalization in about $70 \%$ of the cases, attempt to suicide in about $20 \%$ of the patients, worsening of caregivers' quality of life and higher health care-related and indirect costs. ${ }^{39-41}$ Furthermore, relapses can result in poorer long-term outcomes, ${ }^{42}$ such as disease progression and emergent treatment refractoriness. ${ }^{43,44}$

LAI antipsychotics were developed in order to limit both hidden and overt non-adherence to antipsychotic drugs. LAIs has some known disadvantages such as pain on the injection site, lack of flexibility in dose adjustments and patients' perception of stigma and coercion. ${ }^{40}$ However, they have potential advantages such as complete tracking of the drug consumption and full adherence in early stages of the disease. ${ }^{45,46}$ In addition, LAIs do not need daily administration, which may be perceived by patients as a practical advantage, and minimize the risk of harmful drug use..$^{47,48}$ It has also been suggested that pharmacokinetic (PK) differences associated with the route of administration may be a possible advantage for LAI over oral formulations. The higher bioavailability of LAI formulations may help identify the lower effective dose, reducing unnecessary toxic serum levels of the drug. ${ }^{49}$ Furthermore, a reduced fluctuation of serum drug levels, and therefore a more stable receptor occupancy, ${ }^{50}$ may reduce adverse events. ${ }^{49,51}$ Moreover, in case of sudden treatment interruption, plasmatic drug levels would decrease abruptly. On the contrary, after the discontinuance of the treatment, LAI antipsychotics assure a progressive decrease of the plasma drug levels. This difference might lower the risk of the so-called "super-sensitivity psychosis", a severe disease relapse triggered by sudden antipsychotic withdrawal. ${ }^{52}$ Furthermore, LAIs facilitate the regular contact between patients and physician and allow physicians to rule out non-adherence as a cause of relapse. At last, should a patient miss an injection, there remains some time to act to avert a crisis. ${ }^{53}$

Among LAIs, second-generation long-acting antipsychotics (SGA-LAIs) combine the advantages of SGAs with a long-acting formulation. ${ }^{10}$ The SGA-LAIs available on the market are risperidone LAI (RLAI), olanzapine LAI (OLAI), aripiprazole long-acting one month (AOM) and paliperidone palmitate (PP) long-acting 1 month (PP1M) and 3 month (PP3M). Scientific evidence about superiority of SGA-LAIs to SGA oral formulations is controversial. On one hand, randomized controlled trials (RCTs), considered to be the "gold standard" for clinical trial design, do not support the clinical viewpoint that LAI antipsychotics are generally 
superior to oral formulations in terms of effectiveness, safety and tolerability. On the other hand, observational studies (eg, cohort and mirror studies), that encompass the concept of effectiveness in a naturalistic-pragmatic setting (more representative of real-life clinical practice), show a greater benefit of LAIs over oral antipsychotics. ${ }^{54-57}$ RCTs have high internal validity and allow specific signal detection in carefully selected patient population. Moreover, randomization and blinding of the RCTs can adequately control confounding effects. However, RCTs are frequently affected by selection bias, so they have limited external validity and generalizability to a wider clinical patient population. ${ }^{56}$ Observational naturalistic studies analyze real-world patients, limiting selection bias and improving generalizability and external validity. Also, they include pragmatic outcomes such as hospitalizations and all-cause treatment discontinuation. Nevertheless, this kind of study design can be confounded by factors that vary over time and, without a separate control group, this type of confounding cannot be controlled for. ${ }^{56}$ Therefore, in order to answer questions of clinical efficacy and effectiveness of LAIs in the range of patients generally seen during routine clinical practice, both RCTs and naturalistic studies are required. ${ }^{57}$ About this topic, a recent meta-analysis of head-to-head RCTs comparing the principal SGA-LAIs and their oral counterparts highlighted that high-quality evidence suggests that AOM may provide some small advantages compared with its oral preparation; moderate quality evidence showed that there is no clinical benefit for RLAI; evidence for OLAI was imprecise and therefore not able to rule out neither clinically meaningful superiority nor inferiority vs oral olanzapine; no evidence for PP was available in July $2016 .{ }^{54}$ To achieve stronger evidence and recommendations about the use of SGA-LAIs, more headto-head comparisons between drugs are expected, ${ }^{57}$ such as the European Long-Acting Antipsychotics in Schizophrenia Trial (EULAST), which compares oral and LAI formulations of aripiprazole and paliperidone (NCT02146547). These investigations will provide data for further meta-analytic approaches regarding the relative usefulness of the different drugs and formulations available. Future research and experiences will also help to identify which clinical subpopulation may obtain greater benefit from these new formulations, not only in controlling symptoms but also in terms of cognitive performance, functioning, and quality of life..$^{58}$

\section{Methods}

On August 21, 2017, an electronic search on PubMed about PP3M, without any filter or MESH restriction, was performed, using the following search string: ("3 months" OR "three months" OR "3 monthly" OR "three monthly" OR "3-month" OR "three-month" OR "3-monthly" OR "threemonthly") AND "paliperidone". The query translation of PubMed search engine was as follows: ("3 months" [All Fields] OR "three months" [All Fields] OR "3 monthly" [All Fields] OR "three monthly" [All Fields] OR "3-month" [All Fields] OR "three-month" [All Fields] OR "3-monthly" [All Fields] OR "three-monthly" [All Fields]) AND "paliperidone" [All Fields].

This string was developed because, in scientific literature, PP3M is called in different ways. In particular, the words "three months" (3M) of PP3M have many different spellings listed in the proposed string. These spellings were connected by "OR" logical operator. This string guaranteed a highsensitive search, limiting spelling selection of published works indexed in PubMed. Furthermore, an "AND” logical operator was used to connect these equivalent spellings of $3 \mathrm{M}$ with the word "paliperidone" of PP3M. This logical connective led to a high specific search that selected mostly works on topic.

All kinds of publications (ie, original contributions and reviews) were included. Publications must concern PP3M as principal issue. Publications written in a language other than English were excluded.

\section{Results}

The search described in the previous section provided 38 records. Among them, 16 were excluded: 13 because they did not concern PP3M and 3 because they were not written in English. Thus, this review included 22 records indexed on PubMed: 6 reviews, 1 report, 4 PK studies, 2 cost-effectiveness analyses, 1 open-label clinical trial (OCT), 2 double-blind (DB) RCTs, 5 studies based on these 2 RCTs and 1 observational study. The selection process and a schematic representation of the results are represented in the literature search flowchart (Figure 1).

This review will describe the main findings relating to the formulation, pharmacodynamics, PK, safety, tolerability and efficacy of PP3M, followed by a brief presentation about practical issues encountered with this new formulation. In addition, an overview of possible advantages and disadvantages of PP3M compared with PP1M will be reported. In the final part of this review, PP3M place in therapy and proposals of study designs to further assess this LAI formulation will be discussed. The OCT, the 2 RCTs, the 5 articles based on the RCTs and the observational study are summarized in Table 1.

The OCT was a Phase I, single-dose, randomized, open label study, conducted to investigate the PK, the safety and the tolerability of PP3M in patients with schizophrenia. ${ }^{59}$ 


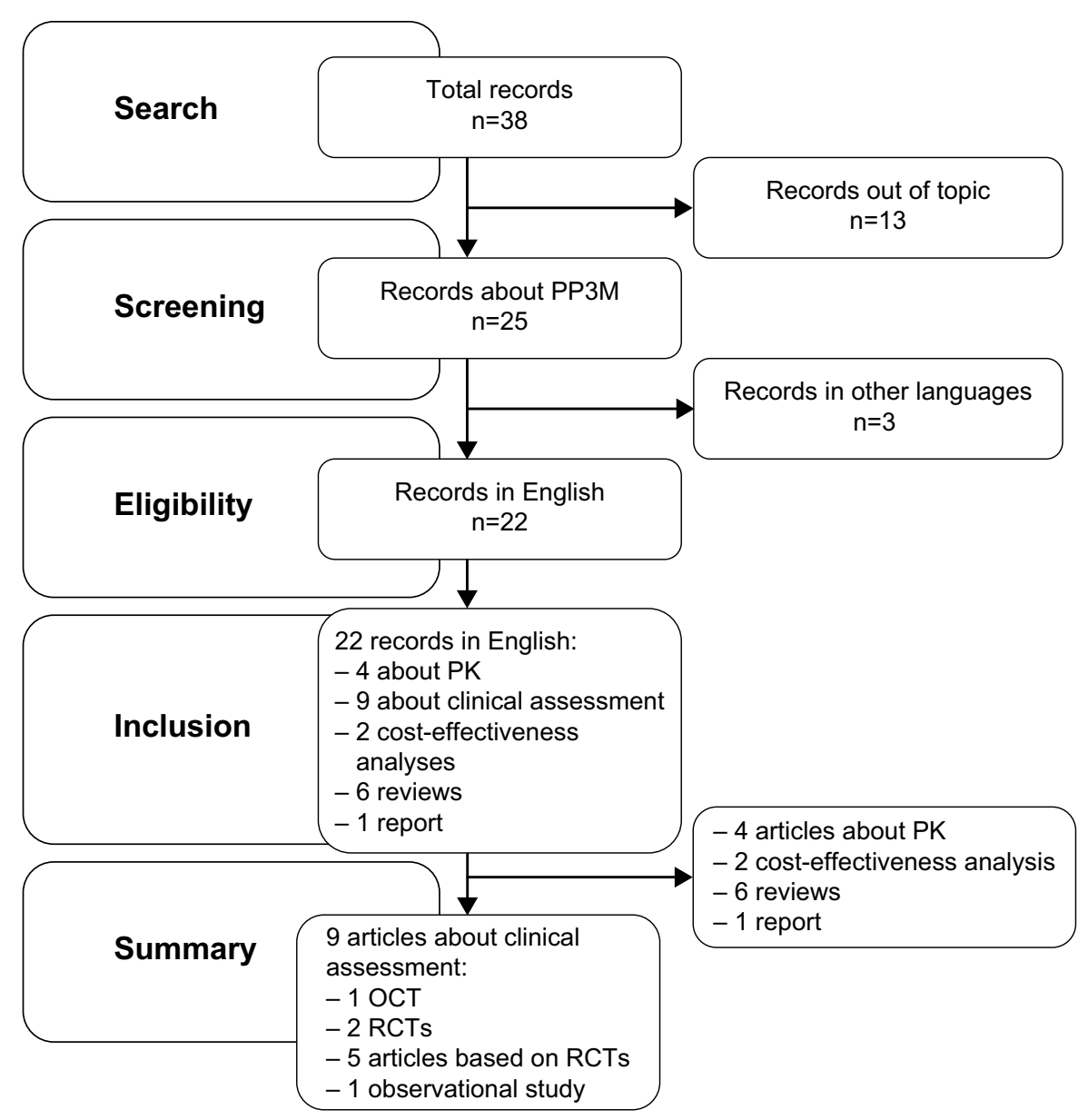

Figure I Literature search flowchart.

Abbreviations: OCT, open-label clinical trial; PK, pharmacokinetics; PP3M, paliperidone palmitate 3-month; RCT, randomized controlled trial.

The first RCT compared PP3M with placebo in order to assess the efficacy and safety of PP3M. ${ }^{60}$ The second RCT aimed to demonstrate non-inferiority of PP3M compared with PP1M in terms of relapse rates, changes in Positive and Negative Syndrome Scale (PANSS) scores, Clinical Global Impression-Severity (CGI-S) score and Personal and Social Performance (PSP) score. ${ }^{61}$ Savitz et al,${ }^{62}$ Katz et al, ${ }^{63}$ Chirila et al, ${ }^{64}$ and Gopal et $\mathrm{al}^{65}$ studied outcome measures within the samples or sub-samples of the 2 previously described RCTs. In details, Savitz et $\mathrm{al}^{62}$ analyzed data derived from the previously mentioned non-inferiority RCT comparing PP3M with PP1M treatment; to investigate symptomatic and functional remission in the DB phase of this RCT, Katz et al ${ }^{63}$ investigated native English-speaking trial participants' and English-speaking investigators' judgments about paliperidone formulations and adherence; Chirila et al ${ }^{64}$ compared occupational status and health care resource use between treatment groups (PP3M vs placebo and PP3M vs PP1M), using data from the whole samples of the 2 RCTs and Gopal et al ${ }^{16}$ evaluated caregiver burden in the 2 RCTs. Weiden et $\mathrm{al}^{66}$ made a post-hoc analysis comparing median time to relapse across the treatment withdrawal arms of 3 different RCTs (Kramer et al, ${ }^{67}$ Hough et al, ${ }^{68}$ and Berwaerts et al ${ }^{60}$ ), which compares the 3 formulations of paliperidone with placebo. Joshi et a ${ }^{69}$ performed an observational retrospective cohort study, using pharmacy and medical claims data of the Symphony Health Solutions database from May 2014 to September 2017. This study described baseline characteristics and treatment patterns of patients with schizophrenia initiated on PP3M in a real-world setting in the USA.

\section{Discussion}

\section{Overview of pharmacology, PKs of} paliperidone palmitate 3-monthly injection Formulation properties

PP3M contains a racemic mixture of the active ingredient paliperidone (9-OH risperidone), an atypical antipsychotic belonging to the chemical class of benzisoxazole derivatives, 
Table I Clinical studies about PP3M

\begin{tabular}{|c|c|c|c|c|}
\hline Study & Aims & $\begin{array}{l}\text { Design, data sources and } \\
\text { duration }\end{array}$ & Sample features & Main results \\
\hline $\begin{array}{l}\text { Ravenstijn } \\
\text { et al }{ }^{59}\end{array}$ & $\begin{array}{l}\text { To assess PP3M: } \\
\text { - PK } \\
\text { - Safety } \\
\text { - Tolerability }\end{array}$ & $\begin{array}{l}\text { Design: OCT } \\
\text { - Phase I study } \\
\text { - Multicenter } \\
\text { - Randomized } \\
\text { - Open-label } \\
\text { - Parallel-group } \\
\text { Duration: from } 12.2 \text { to } \\
\text { I8.2 months }\end{array}$ & $\begin{array}{l}328 \text { patients aged I8-65 years } \\
\text { With: } \\
\text { - Schizophrenia or schizoaffective } \\
\text { disorder (DSM-IV) } \\
\text { - PANSS total score of } \leq 70 \\
\text { Without: } \\
\text { - Substance dependence nor history of } \\
\text { suicide attempt within I } 2 \text { months } \\
\text { - History of NMS or TD }\end{array}$ & $\begin{array}{l}\text { Safety and tolerability: } \\
\text { similar to those of PPIM } \\
\text { PK: results support a once } \\
\text { every } 3 \text { months dosing } \\
\text { interval }\end{array}$ \\
\hline $\begin{array}{l}\text { Berwaerts } \\
\text { et } \mathrm{al}^{60}\end{array}$ & $\begin{array}{l}\text { To assess PP3M: } \\
\text { - Efficacy } \\
\text { - Safety }\end{array}$ & $\begin{array}{l}\text { Design: RCT } \\
\text { PP3M vs placebo: } \\
\text { - Phase III study } \\
\text { - Multicenter } \\
\text { - Randomized } \\
\text { - Open-ended DB final phase } \\
\text { Duration of DB phase } \\
\text { (median time): } \\
\text { - } 5.6 \text { months in the PP3M arm } \\
\text { - } 4.9 \text { months in the placebo arm }\end{array}$ & $\begin{array}{l}506 \text { enrolled patients from } 8 \text { Western and } \\
\text { Asian countries, aged I8-70 years, with: } \\
\text { - Schizophrenia (DSM-IV-TR) for at least } \\
\text { I year before screening } \\
\text { - PANSS total score of } \leq 120 \text { at screening } \\
\text { Without: } \\
\text { - Significant risk of suicidal behavior } \\
\text { - History of substance dependence within } \\
6 \text { months } \\
\text { - History of NMS or TD } \\
305 \text { patients randomized in the DB phase }\end{array}$ & $\begin{array}{l}\text { Efficacy: compared with } \\
\text { placebo PP3M significantly } \\
\text { delayed time to relapse } \\
\text { Safety: profile consistent } \\
\text { with other marketed } \\
\text { paliperidone formulations }\end{array}$ \\
\hline $\begin{array}{l}\text { Savitz } \\
\text { et al }{ }^{61}\end{array}$ & $\begin{array}{l}\text { To test the non- } \\
\text { inferiority of PP3M } \\
\text { to PPIM }\end{array}$ & $\begin{array}{l}\text { Design: RCT } \\
\text { PP3M vs PPIM: } \\
\text { - Phase III study } \\
\text { - Multicenter } \\
\text { - DB final phase } \\
\text { - Parallel-group } \\
\text { - Non-inferiority design } \\
\text { Duration of the DB phase: } \\
\text { II.2 months }\end{array}$ & $\begin{array}{l}\text { I,429 enrolled patients from } 26 \text { Western } \\
\text { and Asian countries, aged I } 8-70 \text { years, } \\
\text { Women: postmenopausal, surgically } \\
\text { sterile, or adequate contraception } \\
\text { Men: adequate contraception } \\
\text { With: } \\
\text { - Schizophrenia (DSM-IV) } \\
\text { - PANSS total score between } 70 \text { and I } 20 \\
\text { Without: } \\
\text { - Any unstable or significant medical or } \\
\text { neurological illness } \\
\text { - Morbid obesity (BMI }>40 \mathrm{~kg} / \mathrm{m}^{2} \text { ) } \\
\text { - Mental retardation } \\
\text { - Risk factors for prolonged QT interval, } \\
\text { torsade de pointes, or sudden death } \\
\text { - History of intolerability, hypersensitivity, } \\
\text { or lack of response to risperidone or } \\
\text { paliperidone } \\
\text { I,0I6 patients entered the DB phase } \\
842 \text { patients completed the DB phase }\end{array}$ & $\begin{array}{l}\text { PP3M was non-inferior to } \\
\text { PPIM in: } \\
\text { - Relapse rates } \\
\text { - Changes in PANSS scores, } \\
\text { CGI-S score and PSP } \\
\text { score }\end{array}$ \\
\hline $\begin{array}{l}\text { Savitz } \\
\text { et al }{ }^{62}\end{array}$ & $\begin{array}{l}\text { To assess } \\
\text { symptomatic and } \\
\text { functional remission } \\
\text { achieved following } \\
\text { PP3M vs PPIM } \\
\text { treatment }\end{array}$ & $\begin{array}{l}\text { Design: RCT } \\
\text { PP3M vs PPIM non-inferiority } \\
\text { design } \\
\text { Data sources: Savitz et al study }{ }^{61} \\
\text { Duration: during DB phase, } \\
\text { II.2 months }\end{array}$ & The same as Savitz 2016 study ${ }^{61}$ & $\begin{array}{l}\text { - PP3M was non-inferior to } \\
\text { PPIM in } \\
\text { - Symptomatic remission } \\
\text { (Andreansen's criteria) } \\
\text { - Functional remission (PSP) } \\
\text { During last } 6 \text { months of the } \\
\text { DB phase }\end{array}$ \\
\hline $\begin{array}{l}\text { Katz } \\
\text { et al }\left.\right|^{63}\end{array}$ & $\begin{array}{l}\text { To quantify } \\
\text { Berwaerts et al }{ }^{60} \\
\text { or Savitz et al } \\
\text { RCT participants' } \\
\text { and investigators' } \\
\text { judgments about } \\
\text { paliperidone } \\
\text { formulations and } \\
\text { adherence }\end{array}$ & $\begin{array}{l}\text { Design: two discrete-choice } \\
\text { experiment surveys: } \\
\text { - One for patients } \\
\text { - One for psychiatrists } \\
\text { Duration: cross-sectional study }\end{array}$ & $\begin{array}{l}438 \text { English-speaking physicians who } \\
\text { participate as investigators in Berwaerts } \\
\text { et a }\left.\right|^{60} \text { and/or Savitz et al }{ }^{61} \text { studies } \\
214 \text { English-speaking patients enrolled in } \\
\text { Australia, Canada and the USA among } \\
\text { the participants of Berwaerts et al }{ }^{60} \text { and } \\
\text { Savitz et al }\left.\right|^{61} \text { trials }\end{array}$ & $\begin{array}{l}\text { Patients and physicians } \\
\text { preferred LAls over oral } \\
\text { antipsychotics } \\
\text { Physicians showed a greater } \\
\text { preference for 3-month over } \\
\text { I-month LAl antipsychotic }\end{array}$ \\
\hline
\end{tabular}


Table I (Continued)

\begin{tabular}{|c|c|c|c|c|}
\hline Study & Aims & $\begin{array}{l}\text { Design, data sources and } \\
\text { duration }\end{array}$ & Sample features & Main results \\
\hline $\begin{array}{l}\text { Chirila } \\
\text { et al }{ }^{64}\end{array}$ & $\begin{array}{l}\text { To compare } \\
\text { occupational status } \\
\text { and health care } \\
\text { resource use between } \\
\text { treatment groups } \\
\text { (PP3M vs placebo and } \\
\text { PP3M vs PPIM) in } \\
\text { Berwaerts et al }{ }^{60} \text { or } \\
\text { Savitz et al }{ }^{61} \text { trials }\end{array}$ & $\begin{array}{l}\text { Design: longitudinal survey } \\
\text { Data sources: Berwaerts et } \mathrm{al}^{60} \\
\text { and Savitz et } \mathrm{al}^{61} \text { studies. Data } \\
\text { deriving from these two RCTs } \\
\text { were analyzed separately } \\
\text { according to the design of the two } \\
\text { original studies } \\
\text { Duration: the same of Berwaerts } \\
\text { et al }{ }^{60} \text { and Savitz et al }{ }^{61} \text { studies }\end{array}$ & $\begin{array}{l}305 \text { patients who were randomized in the } \\
\text { DB phase in Berwaerts et al study }{ }^{60} \\
842 \text { patients who completed the DB phase } \\
\text { in Savitz et al study }{ }^{61}\end{array}$ & $\begin{array}{l}\text { Work: no difference } \\
\text { observed (only a small } \\
\text { number of patients changed } \\
\text { their occupational status } \\
\text { during the studies) } \\
\text { Hospitalization: higher rate } \\
\text { in the placebo group, no } \\
\text { difference between PP3M } \\
\text { and PPIM }\end{array}$ \\
\hline $\begin{array}{l}\text { Gopal } \\
\text { et al }{ }^{65}\end{array}$ & $\begin{array}{l}\text { To evaluate caregiver } \\
\text { burden in Berwaerts } \\
\text { et } a l^{60} \text { and Savitz } \\
\text { et } \mathrm{al}^{61} \text { RCTs }\end{array}$ & $\begin{array}{l}\text { Design: longitudinal survey, with } \\
\text { a mirror image analysis from a } \\
\text { post-hoc analysis of pooled data } \\
\text { Data sources: data derived from } \\
\text { Berwaerts et al }{ }^{60} \text { and Savitz et al }{ }^{61} \\
\text { studies } \\
\text { Duration: the same of Berwaerts } \\
\text { et al }{ }^{60} \text { and Savitz et al }{ }^{61} \text { studies }\end{array}$ & $\begin{array}{l}\text { I,496 caregivers of the patients who } \\
\text { participate to Berwaerts et } \mathrm{al}^{60} \text { and } \\
\text { Savitz et al }{ }^{61} \text { studies } \\
\text { Caregivers who had at least I-hour } \\
\text { contact with the patient per week }\end{array}$ & $\begin{array}{l}\text { Both PPIM and PP3M } \\
\text { may alleviate the caregiver } \\
\text { burden } \\
\text { The mirror image analysis } \\
\text { showed that switching } \\
\text { from an oral antipsychotic } \\
\text { to either PPIM or PP3M } \\
\text { can significantly reduce } \\
\text { caregiver burden }\end{array}$ \\
\hline $\begin{array}{l}\text { Weiden } \\
\text { et } \text { al }^{66}\end{array}$ & $\begin{array}{l}\text { To evaluate the } \\
\text { effect of OP, PPIM } \\
\text { and PP3M on } \\
\text { times to relapse } \\
\text { following medication } \\
\text { discontinuation }\end{array}$ & $\begin{array}{l}\text { Design and data sources: } \\
\text { - Data drawn from Kramer et al, }{ }^{67} \\
\text { Hough et al, }{ }^{68} \text { and Berwaerts } \\
\text { et al }{ }^{60} \text { DB RCTs comparing three } \\
\text { paliperidone formulations (OP, } \\
\text { PPIM and PP3M) with placebo } \\
\text { - Post-hoc analysis of pooled data } \\
\text { - Survival analysis of schizophrenia } \\
\text { relapse in each placebo arm } \\
\text { Duration: the same of Kramer } \\
\text { et al, }{ }^{67} \text { Hough et al, }{ }^{68} \text { and Berwaerts } \\
\text { et al }{ }^{60} \text { studies }\end{array}$ & $\begin{array}{l}\text { I0I patients who were randomized in } \\
\text { the placebo arm during the DB phase of } \\
\text { Kramer et al study }{ }^{67} \\
203 \text { patients who were randomized in } \\
\text { the placebo arm during the DB phase of } \\
\text { Hough et al study }{ }^{68} \\
\text { I } 45 \text { patients who were randomized in } \\
\text { the placebo arm during the DB phase of } \\
\text { Berwaerts et al study }{ }^{60}\end{array}$ & $\begin{array}{l}50 \% \text { of patients who } \\
\text { withdrew treatment } \\
\text { from OP, PPIM or PP3M } \\
\text { remained relapse free } \\
\text { for } \sim 2,6 \text {, and I } 3 \text { months, } \\
\text { respectively } \\
\text { The relapse risk, in terms } \\
\text { of hazard ratio, was } \\
2.08 \text {-fold higher for patients } \\
\text { discontinuing PPIM then for } \\
\text { those discontinuing PP3M }\end{array}$ \\
\hline $\begin{array}{l}\text { Joshi } \\
\text { et al }{ }^{69}\end{array}$ & $\begin{array}{l}\text { To describe baseline } \\
\text { characteristics and } \\
\text { treatment patterns } \\
\text { of patients with } \\
\text { schizophrenia } \\
\text { initiated on PP3M in a } \\
\text { real-world setting }\end{array}$ & $\begin{array}{l}\text { Design: } \\
\text { - Observational retrospective } \\
\text { longitudinal study } \\
\text { - Cohort study } \\
\text { - Index date: the date of the first } \\
\text { approved claim for PP3M } \\
\text { Data sources: pharmacy and } \\
\text { medical PP3M claims from } \\
\text { May } 2014 \text { to September } 2016 \text { in } \\
\text { the Symphony Health Solutions } \\
\text { database } \\
\text { Duration: } 12 \text { months of continuous } \\
\text { clinical activity prior to the } \\
\text { index date }\end{array}$ & $\begin{array}{l}\text { 7,I60 adult patients (I00\%) with at least } \\
\text { one approved PP3M claim 5,362 patients } \\
\text { ( } 74.9 \% \text { ) had continuous clinical activity for } \\
\text { at least I } 2 \text { months prior to the index date } \\
\text { I,545 patients ( } 21.6 \% \text { ) also had at least } \\
\text { one schizophrenia diagnosis anytime } \\
\text { during the study period and were included } \\
\text { in the study (over all PP3M cohort) } \\
\text { I,063 patients ( } 14.8 \% \text { ) had the dose } \\
\text { transition done as labeled (per label } \\
\text { PP3M cohort) }\end{array}$ & $\begin{array}{l}\text { Patients initiated on PP3M } \\
\text { demonstrated decreased } \\
\text { health care resource } \\
\text { utilization and increased } \\
\text { adherence in quarters closer } \\
\text { to PP3M initiation } \\
\text { These patients were } \\
\text { persistent on their PP3M } \\
\text { treatment }\end{array}$ \\
\hline
\end{tabular}

Abbreviations: BMI, body mass index; CGI-S, Clinical Global Impression-Severity; DB, double blind; DSM-IV, Diagnostic and Statistical Manual of Mental Disorders-IV; DSMIV-TR, Diagnostic and Statistical Manual of Mental Disorders-IV Text Revision; LAI, long-acting injectable; NMS, neuroleptic malignant syndrome; OCT, open-label clinical trial; OP, oral paliperidone; PANSS, Positive and Negative Syndrome Scale; PK, pharmacokinetics; PPIM, paliperidone palmitate I-month; PP3M, paliperidone palmitate 3-month; PSP, Personal and Social Performance; RCT, randomized controlled trial; TD, tardive dyskinesia.

derived from risperidone. ${ }^{70,71} \mathrm{PP}$ is the palmitate salt ester of paliperidone. It is very slightly soluble in polar solvent. ${ }^{70,71}$ Tiny drug crystals are created and dispersed in an aqueous suspension (NanoCrystal technology). These crystals are nanoparticles, usually defined as having a size between 1 and $1,000 \mathrm{~nm}$. These tiny drug crystals are dispersed in an aqueous suspension (nanosuspensions), which is the LAI formulation of PP. ${ }^{72}$ The PP3M formulation utilizes NanoCrystal technology similar to the PP1M but with increased particle size, allowing an extended sustained release. ${ }^{59}$ These nanoparticles dissolve slowly after intramuscular (IM) injection before being hydrolyzed to paliperidone by the esterases 
present in muscle tissue. Then paliperidone diffuses into the systemic circulation. ${ }^{72,73} \mathrm{PP} 3 \mathrm{M}$ is available in dose strengths of $273,410,546$ and $819 \mathrm{mg}$ paliperidone palmitate that undergo hydrolysis, resulting in dose strengths of 175, 263, 350 and $525 \mathrm{mg}$ of paliperidone, respectively. ${ }^{72}$

\section{Pharmacodynamics}

Therapeutic efficacy of paliperidone likely occurs through its antagonism of both central dopamine D2 and serotonin 5-HT2A receptors. Plasma concentrations of 10-17 ng/mL were estimated to correspond to $70 \%-80 \%$ occupancy of D2 receptors. ${ }^{74}$ A D2 receptor occupancy of $65 \%-80 \%$ is generally considered optimal, with levels exceeding this conferring an increased risk of extrapyramidal symptoms. ${ }^{75}$ Paliperidone is also an antagonist at $\alpha 1$ - and $\alpha 2$-adrenergic receptors and $\mathrm{H} 1$ histaminergic receptors. ${ }^{75,76}$ This activity profile of paliperidone may explain some of the potential adverse effects of the drug, such as orthostatic hypotension and weight gain. ${ }^{76}$ Unlike risperidone, paliperidone does not block beta adrenoceptors, muscarinic cholinoceptors or peptidergic receptors. This receptor profile, more selctive than the one of risperidone, could avoid further side effects. ${ }^{70}$

\section{Pharmacokinetics}

Nanoparticles of PP3M dissolve slowly after IM injection; release starts as early as day 1 and lasts for up to 18 months. $^{72}$ The paliperidone plasma concentration time profiles for the corresponding PP1M and PP3M doses are similar. The principal differences concern the pre-dose plasma concentrations of PP3M: they are $21 \%$ lower than the concentrations observed following PP1M administration. Mean peak-to-trough ratios are higher following PP3M administration (range: 1.86-2.54) than PP1M administration (range: $1.30-1.63) .{ }^{59}$ With regard to metabolism and elimination, information from the studies of oral paliperidone are reported: $\sim 59 \%$ of a single dose of the drug is excreted unchanged in the urine; $\sim 80 \%$ of the radioactivity related to a single oral dose of $14 \mathrm{C}$ paliperidone is recovered in the urine and $11 \%$ in the feces, indicating a lack of extensive hepatic metabolization. ${ }^{70}$ Results obtained in in vitro studies suggest that CYP2D6 and CYP3A4 may be implicated in the metabolism of paliperidone, although no evidence of their role derive from in vivo studies: inhibitors or inducers of CYP2D6 and CYP3A4 do not significantly influence paliperidone plasma levels and no significant induction or inhibitory properties of paliperidone on the cytochrome system have been demonstrated..$^{59}$
Table 2 Conversion between PPIM and PP3M doses

\begin{tabular}{|c|c|c|c|}
\hline \multicolumn{2}{|l|}{ PPIM dose } & \multicolumn{2}{|l|}{ PP3M dose } \\
\hline $\begin{array}{l}\text { Paliperidone } \\
\text { palmitate }(\mathbf{m g})\end{array}$ & $\begin{array}{l}\text { Paliperidone } \\
\text { (mg eq) }\end{array}$ & $\begin{array}{l}\text { Paliperidone } \\
\text { palmitate (mg) }\end{array}$ & $\begin{array}{l}\text { Paliperidone } \\
\text { (mg eq) }\end{array}$ \\
\hline 78 & 50 & 273 & 175 \\
\hline 117 & 75 & 410 & 263 \\
\hline 156 & 100 & 546 & 350 \\
\hline 234 & 150 & 819 & 525 \\
\hline
\end{tabular}

Note: Data from European Medicine Agency. ${ }^{83}$

Abbreviations: $\mathrm{mg}$ eq, milligram equivalent; PPIM, paliperidone palmitate I-month injection; PP3M, paliperidone palmitate 3-month injection.

\section{Dosing and switching}

PP3M injections should be started at a dose 3.5-fold multiple of the preceding dose of PP1M, and administered in either the deltoid or the gluteal muscle at the time scheduled for the next PP1M dose. ${ }^{72}$ Available marketed doses are listed in Table 2.

Treatment with PP3M should only be initiated in patients who had adequately responded to and tolerated treatment with PP1M for at least 4 months. ${ }^{72}$ Due to the slow release profile, treatment with PP3M is not indicated for use in acutely symptomatic patients or in patients who are transitioning from oral or other, non-PP1M, LAI antipsychotic therapy. ${ }^{72}$ It is recommended that the last $2 \mathrm{PP} 1 \mathrm{M}$ doses prior to switching to PP3M are the same and patients are supposed to be clinically stable at the end of the PP1M dosing before transitioning to PP3M. ${ }^{72}$ According to PK simulations, during maintenance therapy of PP3M, changes in plasma concentrations allow a flexible dosing window of 2 weeks for regularly scheduled 3-monthly injections (Table 3 ). ${ }^{72}$

\section{PP3M injection procedure}

One significant difference between the preparation of PP1M and PP3M is the force of shaking required to re-suspend the syringe contents. The PP3M syringe must be shaken vigorously for at least 15 seconds with a loose wrist before

Table 3 Management of missed PP3M injections

\begin{tabular}{|c|c|}
\hline $\begin{array}{l}\text { Time from the last } \\
\text { PP3M injection, months }\end{array}$ & $\begin{array}{l}\text { Management with PP injectable } \\
\text { formulations }\end{array}$ \\
\hline $3.5-4$ & Resume PP3M injection as soon as possible \\
\hline $4-9$ & $\begin{array}{l}\text { Reinitiate the regimen with PPIM on } \\
\text { days I and } 8 \text {; reinitiate PP } 3 \text { M injections } \\
\text { after } 4 \text { weeks }\end{array}$ \\
\hline$>9$ & $\begin{array}{l}\text { Reinitiate the regimen with PPIM on } \\
\text { days I and } 8 \text {, followed by at least } 3 \text { doses } \\
\text { of PPIM; resume PP3M injections on a } \\
\text { 3-monthly cycle (full new cycle) }\end{array}$ \\
\hline
\end{tabular}

Note: Data from European Medicine Agency. ${ }^{83}$

Abbreviations: PP, paliperidone palmitate; PPIM, paliperidone palmitate I-month injection; PP3M, paliperidone palmitate 3-month injection. 
injecting the formulation to ensure a homogenous suspension. Improper shaking could result in clumping and inability to express the entire medication content from the syringe barrel. ${ }^{72}$ Furthermore, a suitable syringe must be used: in the RCT comparing PP3M and PP1M, the use of a shorter syringe and the consequent lower dose administration of PP3M caused the exclusion of some patients from the study. ${ }^{61,62}$

\section{Clinical efficacy, safety and tolerability of PP for schizophrenia}

Efficacy and hospitalization rate

Efficacy of PP3M was evaluated against placebo ${ }^{60}$ and in terms of non-inferiority against $\mathrm{PP} 1 \mathrm{M}^{61}$ in 2 different $\mathrm{DB}$ RCTs summarized in Table 1. The first study was stopped by an independent data monitoring committee for greater efficacy of PP3M compared to placebo: during the DB phase, $29 \%$ of patients in the placebo group experienced a relapse event against $9 \%$ in the group receiving PP3M. ${ }^{60}$ The final data analysis included 305 patients (PP3M: $n=160$; placebo: $\mathrm{n}=145$ ) and showed superiority of PP3M over placebo in delaying time to relapse of schizophrenia symptoms $(P<0.001$; hazard ratio $=3.81 ; 95 \% \mathrm{CI}, 2.08-6.99)$, a result confirmed by Cox proportional hazards models. ${ }^{60}$ Furthermore, Weiden et al post-hoc study ${ }^{66}$ showed longer time to relapse after PP3M treatment discontinuation compared to that of oral paliperidone and PP1M: in particular, after suspension of the treatment, $50 \%$ of patients treated with PP3M remained relapse free for $\sim 13$ months, instead of 6 months with PP1M treatment withdrawal. Also, according to this study, the relapse risk (hazard ratio) was 2.08 higher for patients discontinuing PP1M than for those discontinuing PP3M. ${ }^{66}$ However, as these data come from a descriptive post-hoc analysis and not a meta-analysis of the datasets of the three different RCTs (Kramer et al, ${ }^{67}$ Hough et al ${ }^{68}$ and Berwaerts et $\mathrm{al}^{60}$ ), caution must be used when interpreting this study. Furthermore, this was not a head-to-head discontinuation RCT comparing oral paliperidone, PP1M and PP3M in the same trial; therefore, the evidence of this post-hoc analysis has strong study design and generalizability limitations.

The non-inferiority Phase III $\mathrm{RCT}^{61}$ demonstrated that PP3M-treated group had relapse rates similar to PPM1treated group, based on Kaplan-Meier estimates. Variations from DB baseline in Positive and Negative Symptom Scale (PANSS) total score and subscale scores, in Clinical CGI-S and in PSP scores were similar in the two experimental groups. ${ }^{61}$ Furthermore, PP3M and PP1M treatments showed comparable symptomatic (defined according to Andreasen's criteria on PANSS) and functional remissions (PSP $>70$ ) during the last 6 months of DB phase. In addition, most patients who achieved remission at DB baseline maintained their remission status throughout the DB phase. ${ }^{62}$

Moreover, health care resource use was studied in the 2 described RCTs ${ }^{60,61}$ in terms of hospitalization odds. ${ }^{64}$ The placebo group showed a higher rate of hospitalization for either psychiatric and social reasons or social reason alone compared to PP3M. ${ }^{64}$ No difference in terms of hospitalizations was observed between PP3M and PP1M groups. ${ }^{64}$

\section{Safety and tolerability}

Safety and tolerability were examined in the 2 previously described RCTs and in the Phase I OCT. ${ }^{59}$ The latter one showed that headache and nasopharyngitis were the most common $(>7 \%)$ treatment-emergent adverse events (TEAEs) and described a safety and tolerability profile similar to those of PP1M. ${ }^{59}$ Compared with placebo, PP3M treatment demonstrated a similar proportion on TEAEs developed during the DB phase of the study: $62 \%$ of the subjects who were treated with PP3M injections and $58 \%$ of the subjects who received placebo injections had at least one TEAE. TEAEs noted more frequently in the group receiving PP3M than in the placebo group were headache ( $9 \%$ vs $4 \%$ ), weight increase ( $9 \%$ vs $3 \%)$, nasopharyngitis ( $6 \%$ vs $1 \%$ ) and akathisia (4\% vs $1 \%) .{ }^{60}$ In the non-inferiority Phase III RCT, safety and tolerability profiles of PP3M and PP1M were comparable over the whole DB phase of the study. Withdrawal rates due to TEAEs were low and comparable for both treatments. ${ }^{61}$ Serious TEAEs were mostly of a psychiatric nature and similar between both groups. ${ }^{61}$ Weight gain, nasopharyngitis and anxiety were the most common TEAEs in both groups. ${ }^{61}$ Other TEAEs such as extrapyramidal symptoms, suicidality, agitation and aggression, somnolence and sedation, tachycardia, orthostatic hypotension, QTc interval prolongation, potentially prolactin-related and weight gain-related TEAEs had a similar frequency in both experimental groups. ${ }^{61}$

\section{Pregnancy}

With its release during 18 months from the injection, PP3M makes more likely fetal exposition to paliperidone. However, few data about paliperidone effects in pregnancy are available in scientific literature. Two case reports of women in treatment with PP1M during pregnancy reported no congenital malformation and no perinatal complications of the newborns. ${ }^{77,78}$

\section{Other features of PP3M and ethical implications \\ Quality of life, satisfaction and adherence}

To our knowledge, no studies about quality of life, satisfaction and adherence of PP3M-treated patients with 
schizophrenia have been performed, yet. Longer follow-up studies should be carried out in order to compare switching from PP1M to PP3M treatment.

\section{Caregiver burden}

A study by Gopal et $\mathrm{a}^{65}$ showed that switching from an oral antipsychotic to either PP1M or PP3M can significantly reduce caregiver burden. This mirror image study was performed on data derived from the non-inferiority Phase III RCT comparing PP1M and PP3M. ${ }^{61}$ For this reason, both treatment groups received a monthly injection and caregiver burden reduction because diminished number of administrations was not detectable. ${ }^{65}$ To our knowledge, no studies on this topic in the transition from PP1M to PP3M in a realworld setting are available.

\section{Antipsychotic preference according to formulation}

Katz et $\mathrm{al}^{63}$ analyzed preferences between oral antipsychotic treatments, PP1M and PP3M with a survey performed by English native speaking and English-speaking physicians who participated in the $2 \operatorname{RCTs}^{60,61}$ as previously described.

According to this study, patients and physicians preferred LAIs over oral antipsychotics and were willing to accept reduced efficacy in exchange for switching from an oral formulation to an LAI. Physicians showed a greater preference for 3-month over 1-month LAI. ${ }^{63}$

\section{Occupational status variation}

Chirila et $\mathrm{al}^{64}$ described the occupational status of patients who participated in the 2 RCTs $^{60,61}$ as previously described. According to that study, no significant differences in terms of variation of the occupational status were observed between PP3M and placebo and PP3M and PP1M treatments, probably because of the short time of follow-up and consequently the small number of patients who changed their occupational status during the 2 trials. ${ }^{64}$ Although not statistically significant, at the end of the follow-up period (from week 41 until week 53), improvement from baseline in occupational status was slightly higher in the PP $3 \mathrm{M}$ than in the PP1M group. ${ }^{64}$

\section{Ethical implications}

Both the RCT comparing PP3M with placebo ${ }^{60}$ and the RCT comparing PP3M with PP1 $1 \mathrm{M}^{61}$ were conducted in compliance with the Declaration of Helsinki, consistent with Good Clinical Practices and applicable regulatory requirements and with the approval of independent ethical committees of the participant center. Nonetheless, some ethical critics were made against these studies. First of all, comparing a new drug with placebo might be considered ethically debatable and clinically irrelevant when effective agents are available. ${ }^{79}$ In this particular case, the European Medicines Agency (EMA) pointed out the relevance of placebo-controlled studies when assessing the efficacy of new LAIs, arguing that recent schizophrenia trials showed only minimal differences between active treatments and placebo, and therefore an assessment of the absolute effect is required to establish efficacy. ${ }^{80}$ With reference to the study comparing PP3M and PP1M, it has been pointed out that, as there is no validated and shared method of choice of the non-inferiority margin, the demonstration of non-inferiority leaves uncertainty on whether the 2 drugs are really equivalent and does not establish whether the new drug tested is associated with additional benefits over the control. ${ }^{79}$

\section{Advantages and disadvantages of PP3M compared with PPIM}

Advantages and disadvantages of PP3M, compared with PP1M treatment, are summarized in Figure 2.

One of the most positive features of PP3M is notable that patients need to receive an injection just 4 times per year. The lower number of injections is more comfortable for patients, especially for those patients who cannot easily reach the place of administration. Furthermore, less time is needed for drug administration so that saved time and resources can be available for other therapeutic activities, for example, rehabilitation. At the same time, psychiatric services with poor human resources should control the risk to visit the patient exclusively 4 times a year on the day of PP3M administration and not according to the health needs of the patient. In terms of costs, three doses of PP1M cost as much as the equivalent dose of 1 PP3M injection, but the administration costs are reduced to one-third. Moreover, 2 economic studies evaluated cost-utility and costeffectiveness simulations on the use of PP3M in Spain and in the Netherlands. ${ }^{81,82}$ According to these studies, PP3M resulted to be cost-effective for treating chronic schizophrenia and dominated PP1M in all analyses. ${ }^{81,82}$

Finally, PP3M administration protocol admits more flexible delays in PP3M injections interval compared with PP1M. In fact, according to PP3M administration regimen, 2 weeks of delays after 3 planned months of inter-injections interval can be tolerated instead of 1 week with PP1M.

The main disadvantages of PP3M can be summarized as follows. First of all, despite the tolerance demonstrated by patients during the PP1M phase of treatment, adverse events related to paliperidone therapy might appear during PP3M treatment. The control of these side effects, especially if 


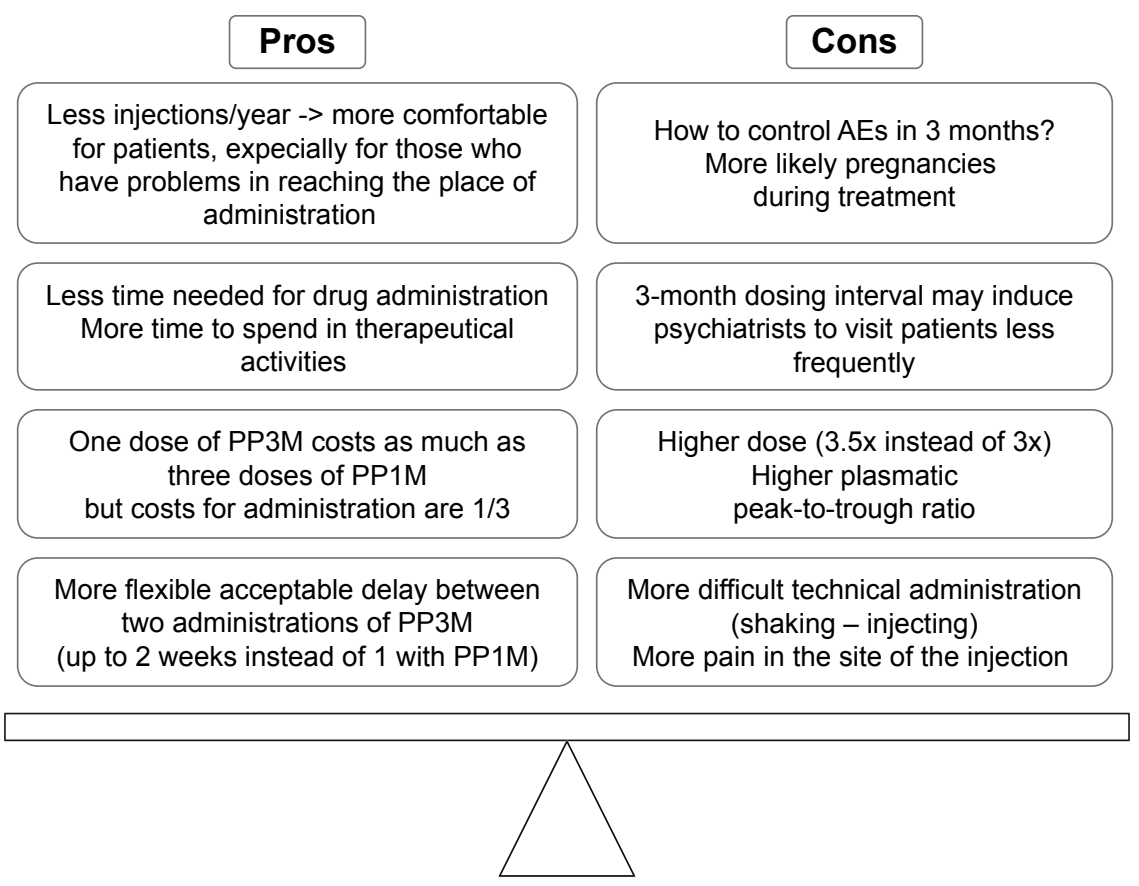

Figure 2 Comparison between PP3M and PPIM pros and cons.

Abbreviations: AE, adverse event; PPIM, paliperidone palmitate I-month; PP3M, paliperidone palmitate.

starting soon after a PP3M administration, could be a clinical challenge for psychiatrists but, above all, a real health problem for patients. In addition, a 3-month dosing interval may induce psychiatrists to visit patient less frequently, for example only in concomitance with PP3M administration. Even if PK studies demonstrated a similar exposure to paliperidone with PP3M and PP1M, a 3.5-fold higher dose of PP3M is equivalent to a single dose of PP1M. In other words, a larger quantity of PP is injected in patients treated with PP3M. These data, in addition to the known higher plasmatic mean peak-to-trough ratio of PP3M, could lead to long-term adverse effects, somewhat different from those of PP1M.
PP3M injections need more technical carefulness to be correctly administered compared with PP1M procedure. In fact, a longer period of shaking and a longer injecting procedure are required. Finally, the larger volume administered with PP3M could be more painful in the injected muscle tissue.

\section{Possible study designs to further assess PP3M}

Further studies are needed to asses PP3M features more clearly. Some proposals of study design are described in Figure 3.

To our knowledge, the only observational study on PP3M is a retrospective cohort study that chose the date of the

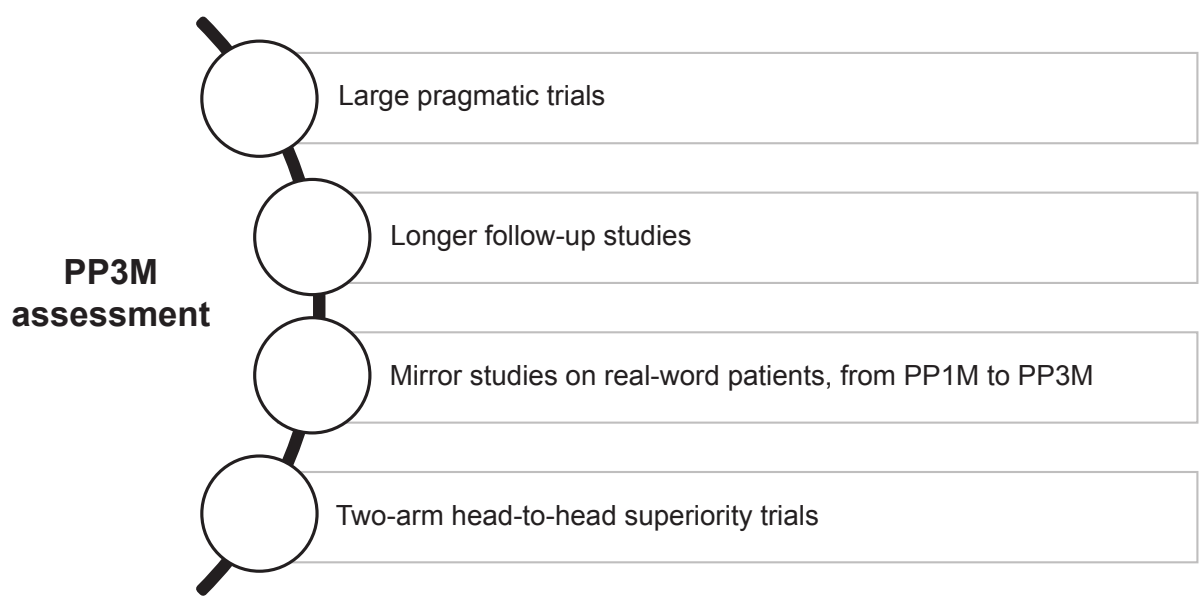

Figure 3 Some possible study designs needed to further assess PP3M.

Abbreviations: PPIM, paliperidone palmitate I-month; PP3M, paliperidone palmitate 3-month. 
first approved claim for PP3M as the index date. ${ }^{69}$ According to its experimental design, this study does not inform about the effect of PP3M treatment. In this scenery, large pragmatic trials and mirror studies on real-world patients switching from PP1M to PP3M would be useful in defining advantages and disadvantages of PP3M confronted with PP1M. Furthermore, 2-arm head-to-head superiority trials could directly compare PP3M with PP1M and with other SGA-LAIs. Regardless of the study design adopted, longer follow-ups are needed to study PP3M treatment safety and impact on patients' adherence, functioning, quality of life and satisfaction. Finally, further studies are necessary to determine which subgroups of patients would most beneficiate from PP3M treatment.

\section{Conclusion}

In conclusion, PP3M is the only 3-month LAI antipsychotic available on the market. This makes it a unique option of treatment, which can be chosen both in early and advanced phases of illness. Nonetheless, further studies are needed to assess long-term safety, impact on quality of life and on functioning and to define patients' sub-populations that would most beneficiate from this new option of treatment.

\section{Disclosure}

The authors report no conflicts of interest in this work.

\section{References}

1. McGrath J, Saha S, Chant D, Welham J. Schizophrenia: a concise overview of incidence, prevalence, and mortality. Epidemiol Rev. 2008; 30(1):67-76.

2. Vos T, Flaxman AD, Naghavi M, et al. Years lived with disability (YLDs) for 1160 sequelae of 289 diseases and injuries 1990-2010: a systematic analysis for the Global Burden of Disease Study 2010. Lancet. 2013;380(9859):2163-2196.

3. Murray CJ, Lopez AD, Jamison DT. The global burden of disease in 1990: summary results, sensitivity analysis and future directions. Bull World Health Org. 1994;72(3):495-509.

4. Carrà G, Cazzullo CL, Clerici M. The association between expressed emotion, illness severity and subjective burden of care in relatives of patients with schizophrenia. Findings from an Italian population. BMC Psychiatry. 2012;12(1):140.

5. National Collaborating Centre for Mental Health UK. Psychosis and Schizophrenia in Adults: Treatment and Management: Updated Edition 2014; London: National Institute for Health and Care Excellence (UK) NICE guidelines updated in 2014.

6. Knapp M, Mangalore R, Simon J. The global costs of schizophrenia. Schizophr Bull. 2004;30(2):279-293.

7. Howes OD, Murray RM. Schizophrenia: an integrated sociodevelopmental-cognitive model. Lancet. 2014;383(9929):1677-1687.

8. Saha S, Chant D, McGrath J. A systematic review of mortality in schizophrenia: is the differential mortality gap worsening over time? Arch Gen Psychiatry. 2007;64(10):1123-1131.

9. Wiersma D, Wanderling J, Dragomirecka E, et al. Social disability in schizophrenia: its development and prediction over 15 years in incidence cohorts in six European centres. Psychol Med. 2000;30(05): $1155-1167$.
10. Montemagni C, Frieri T, Rocca P. Second-generation long-acting injectable antipsychotics in schizophrenia: patient functioning and quality of life. Neuropsychiat Dis Treat. 2016;12:917-929.

11. Almond S, Knapp M, Francois C, Toumi M, Brugha T. Relapse in schizophrenia: costs, clinical outcomes and quality of life. $\mathrm{Br} \mathrm{J}$ Psychiatry. 2004;184(4):346-351.

12. Ascher-Svanum H, Zhu B, Faries DE, et al. The cost of relapse and the predictors of relapse in the treatment of schizophrenia. BMC Psychiatry. 2010;10(1):2.

13. Weiden PJ, Olfson M. Cost of relapse in schizophrenia. Schizophr Bull. 1995;21(3):419-429.

14. Wyatt RJ. Research in schizophrenia and the discontinuation of antipsychotic medications. Schizophr Bull. 1997;23(1):3-9.

15. Lieberman JA, Alvir JM, Koreen A, et al. Psychobiologic correlates of treatment response in schizophrenia. Neuropsychopharmacology. 1996;14(Suppl 3):13S-21S.

16. Birchwood M, Todd P, Jackson C. Early intervention in psychosis. The critical period hypothesis. Br J Psychiatry Suppl. 1998;172(33):53-59.

17. McEvoy JP. The importance of early treatment of schizophrenia. Behav Healthc. 2007;27(4):40-43.

18. Murray RM, Quattrone D, Natesan S, et al. Should psychiatrists be more cautious about the long-term prophylactic use of antipsychotics? Br J Psychiatry. 2016;209(5):361-365.

19. Pantelis C, Yücel M, Wood SJ, McGorry PD, Velakoulis D. Early and late neurodevelopmental disturbances in schizophrenia and their functional consequences. Aust N Z J Psychiatry. 2003;37(4):399-406.

20. Perkins DO, Gu H, Boteva K, Lieberman JA. Relationship between duration of untreated psychosis and outcome in first-episode schizophrenia: a critical review and meta-analysis. Am J Psychiatry. 2005; 162(10): 1785-1804.

21. Hasan A, Falkai P, Wobrock T, et al; World Federation of Societies of Biological Psychiatry (WFSBP) Task Force on Treatment Guidelines for Schizophrenia. World federation of societies of biological psychiatry (WFSBP) guidelines for biological treatment of schizophrenia, part 1: update 2012 on the acute treatment of schizophrenia and the management of treatment resistance. World J Biol Psychiatry. 2012; 13(5):318-378.

22. Hasan A, Falkai P, Wobrock T, et al; WFSBP Task force on Treatment Guidelines for Schizophrenia. World federation of societies of biological psychiatry (WFSBP) guidelines for biological treatment of schizophrenia, part 2: update 2012 on the long-term treatment of schizophrenia and management of antipsychotic-induced side effects. World J Biol Psychiatry. 2013;14(1):2-44.

23. Lindenmayer JP, Liu-Seifert H, Kulkarni PM, et al. Medication nonadherence and treatment outcome in patients with schizophrenia or schizoaffective disorder with suboptimal prior response. J Clin Psychiatry. 2009;70(7):990-996.

24. Suzuki T, Uchida H, Takeuchi H, Tsuboi T, Hirano J, Mimura M. A review on schizophrenia and relapse a quest for user-friendly psychopharmacotherapy. Hum Psychopharmacol. 2014;29(5):414-426.

25. Emsley R, Chiliza B, Asmal L, Harvey BH. The nature of relapse in schizophrenia. BMC Psychiatry. 2013;13(1):50.

26. Coldham EL, Addington J, Addington D. Medication adherence of individuals with a first episode of psychosis. Acta Psychiatr Scand. 2002;106(4):286-290.

27. Tiihonen J, Haukka J, Taylor M, Haddad PM, Patel MX, Korhonen P. A nationwide cohort study of oral and depot antipsychotics after first hospitalization for schizophrenia. Am J Psychiatry. 2011;168(6): 603-609.

28. Miller BJ. A review of second-generation antipsychotic discontinuation in first-episode psychosis. J Psychiatr Pract. 2008;14(5):289-300.

29. Miller BJ, Bodenheimer C, Crittenden K. Second-generation antipsychotic discontinuation in first episode psychosis: an updated review. Clin Psychopharmacol Neurosci. 2011;9(2):45-53.

30. Novick D, Haro JM, Suarez D, Perez V, Dittmann RW, Haddad PM. Predictors and clinical consequences of non-adherence with antipsychotic medication in the outpatient treatment of schizophrenia. Psychiatry Res. 2010;176(2-3):109-113. 
31. Velligan DI, Lam F, Ereshefsky L, Miller AL. Psychopharmacology: perspectives on medication adherence and atypical antipsychotic medications. Psychiatr Serv. 2003;54(5):665-667.

32. Lieberman JA, Stroup TS, McEvoy JP, et al; Clinical Antipsychotic Trials of Intervention Effectiveness (CATIE) Investigators. Effectiveness of antipsychotic drugs in patients with chronic schizophrenia. N Engl J Med. 2005;353(12):1209-1223.

33. Kahn RS, Fleischhacker WW, Boter H, et al; EUFEST study group. Effectiveness of antipsychotic drugs in first-episode schizophrenia and schizophreniform disorder: an open randomised clinical trial. Lancet. 2008;371(9618):1085-1097.

34. Di Matteo MR. Variations in patients' adherence to medical recommendations: a quantitative review of 50 years of research. Med Care. 2004;42(3):200-209.

35. Jónsdóttir H, Opjordsmoen S, Birkenaes AB, et al. Medication adherence in outpatients with severe mental disorders: relation between self-reports and serum level. J Clin Psychopharmacol. 2010;30(2):169-175.

36. Dassa D, Boyer L, Benoit M, Bourcet S, Raymondet P, Bottai T. Factors associated with medication non-adherence in patients suffering from schizophrenia: a cross-sectional study in a universal coverage healthcare system. Aust N Z J Psychiatry. 2010;44(10):921-928.

37. Velligan DI, Wang M, Diamond $P$, et al. Relationships among subjective and objective measures of adherence to oral antipsychotic medications. Psychiatr Serv. 2007;58(9):1187-1192.

38. Kane JM, Kishimoto T, Correll CU. Non-adherence to medication in patients with psychotic disorders: epidemiology, contributing factors and management strategies. World Psychiatry. 2013;12(3):216-226.

39. Haddad PM, Brain C, Scott J. Nonadherence with antipsychotic medication in schizophrenia: challenges and management strategies. Patient Relat Outcome Meas. 2014;5:43-62.

40. Brissos S, Veguilla MR, Taylor D, Balanzá-Martinez V. The role of long-acting injectable antipsychotics in schizophrenia: a critical appraisal. Ther Adv Psychopharmacol. 2014;4(5):198-219.

41. Lauber C, Eichenberger A, Luginbühl P, Keller C, Rössler W. Determinants of burden in caregivers of patients with exacerbating schizophrenia. Eur Psychiatry. 2003;18(6):285-289.

42. Leucht S, Tardy M, Komossa K, et al. Antipsychotic drugs versus placebo for relapse prevention in schizophrenia: a systematic review and meta-analysis. Lancet. 2012;379(9831):2063-2071.

43. Wiersma D, Nienhuis FJ, Slooff CJ, Giel R. Natural course of schizophrenic disorders: a 15-year followup of a Dutch incidence cohort. Schizophr Bull. 1998;24(1):75-85.

44. Emsley R, Oosthuizen P, Koen L, Niehaus D, Martinez L. Comparison of treatment response in second-episode versus first-episode schizophrenia. J Clin Psychopharmacol. 2013;33(1):80-83.

45. Llorca PM, Abbar M, Courtet P, Guillaume S, Lancrenon S, Samalin L. Guidelines for the use and management of long-acting injectable antipsychotics in serious mental illness. BMC Psychiatry. 2013;13:340.

46. Tiihonen J, Haukka J, Taylor M, Haddad PM, Patel MX, Korhonen P. A nationwide cohort study of oral and depot antipsychotics after first hospitalization for schizophrenia. Am J Psychiatry. 2011;168(6): 603-609.

47. Patel MX, David AS. Why aren't depot antipsychotics prescribed more often and what can be done about it? Adv Psychiatr Treat. 2005;11(3):203-211.

48. Taylor M, Ng KY. Should long-acting (depot) antipsychotics be used in early schizophrenia? A systematic review. Aust N Z J Psychiatry. 2013;47(7):624-630.

49. Ereshefsky L, Mascarenas CA. Comparison of the effects of different routes of antipsychotic administration on pharmacokinetics and pharmacodynamics. J Clin Psychiatry. 2003;64(16):18-23.

50. Gefvert O, Eriksson B, Persson P, et al. Pharmacokinetics and D2 receptor occupancy of long-acting injectable risperidone (Risperdal Consta $^{\mathrm{TM}}$ ) in patients with schizophrenia. Int J Neuropsychopharmacol. 2005;8(1):27-36.

51. Whitworth AB, Fleischhacker WW. Adverse effects of antipsychotic drugs. Curr Opin Psychiatry. 1994;7(1):71-75.
52. Moncrieff J. Does antipsychotic withdrawal provoke psychosis? Review of the literature on rapid onset psychosis (supersensitivity psychosis) and withdrawal-related relapse. Acta Psychiatr Scand. 2006; 114(1):3-13.

53. Kane JM, Garcia-Ribera C. Clinical guideline recommendations for antipsychotic long-acting injections. Br J Psychiatry Suppl. 2009;52: S63-S67.

54. Ostuzzi G, Bighelli I, So R, Furukawa TA, Barbui C. Does formulation matter? A systematic review and meta-analysis of oral versus longacting antipsychotic studies. Schizophr Res. 2016;183:10-21.

55. Biagi E, Capuzzi E, Colmegna F, et al. Long-acting injectable antipsychotics in schizophrenia: literature review and practical perspective, with a focus on aripiprazole once-monthly. Adv Ther. 2017;34(5): 1036-1048.

56. Correll CU, Kishimoto T, Kane JM. Randomized controlled trials in schizophrenia: opportunities, limitations, and trial design alternatives. Dialogues Clin Neurosci. 2011;13(2):155-172.

57. Fagiolini A, Rocca P, De Giorgi S, Spina E, Amodeo G, Amore M. Clinical trial methodology to assess the efficacy/effectiveness of longacting antipsychotics: Randomized controlled trials vs naturalistic studies. Psychiatry Res. 2017;247:257-264.

58. Bernardo M, Bioque M. Three-month paliperidone palmitate-a new treatment option for schizophrenia. Expert Rev Clin Pharmacol. 2016; 9(7):899-904.

59. Ravenstijn P, Remmerie B, Savitz A, et al. Pharmacokinetics, safety, and tolerability of paliperidone palmitate 3-month formulation in patients with schizophrenia: a phase-1, single-dose, randomized, open-label study. J Clin Pharmacol. 2016;56(3):330-339.

60. Berwaerts J, Liu Y, Gopal S, et al. Efficacy and safety of the 3-month formulation of paliperidone palmitate vs placebo for relapse prevention of schizophrenia: a randomized clinical trial. JAMA Psychiatry. 2015; 72(8):830-839.

61. Savitz AJ, Xu H, Gopal S, et al. Efficacy and safety of paliperidone palmitate 3-month formulation for patients with schizophrenia: a randomized, multicenter, double-blind, noninferiority study. Int $J$ Neuropsychopharmacol. 2016;19(7):Pyw018.

62. Savitz AJ, Xu H, Gopal S, Nuamah I, Hough D, Mathews M. Paliperidone palmitate 3-month treatment results in symptomatic remission in patients with schizophrenia: a randomized, multicenter, double-blind, and noninferiority study. Intern Clin Psychopharmacol. 2017;32(6):329-336.

63. Katz EG, Hauber B, Gopal S, et al. Physician and patient benefit-risk preferences from two randomized long-acting injectable antipsychotic trials. Patient Prefer Adherence. 2016;10:2127-2139.

64. Chirila C, Nuamah I, Woodruff K. Health care resource use analysis of paliperidone palmitate 3 month injection from two phase 3 clinical trials. Curr Med Res Opin. 2017;33(6):1083-1090.

65. Gopal S, Xu H, McQuarrie K, et al. Caregiver burden in schizophrenia following paliperidone palmitate long acting injectables treatment: pooled analysis of two double-blind randomized phase three studies. NPJ Schizophr. 2017;3(1):23.

66. Weiden PJ, Kim E, Bermak J, Turkoz I, Gopal S, Berwaerts J. Does halflife matter after antipsychotic discontinuation? A relapse comparison in schizophrenia with 3 different formulations of paliperidone. $J$ Clin Psychiatry. 2017;78(7):e813-e820.

67. Kramer M, Simpson G, Maciulis V, et al. Paliperidone extended-release tablets for prevention of symptom recurrence in patients with schizophrenia: a randomized, double-blind, placebo-controlled study. J Clin Psychopharmacol. 2007;27(1):6-14.

68. Hough D, Gopal S, Vijapurkar U, Lim P, Morozova M, Eerdekens M. Paliperidone palmitate maintenance treatment in delaying the time-to-relapse in patients with schizophrenia: a randomized, doubleblind, placebo-controlled study. Schizophr Res. 2010;116(2-3): 107-117.

69. Joshi K, Lafeuille MH, Brown B, et al. Baseline characteristics and treatment patterns of patients with schizophrenia initiated on onceevery-three-months paliperidone palmitate in a real-world setting. Curr Med Res Opin. 2017;33(10):1763-1772. 
70. European Medicines Agency. Trevicta (paliperidone palmitate) prolonged release suspension for injection: EU summary of product characteristics. 2016. Available from: http://www.ema.europa.eu/. Accessed April 30, 2017.

71. Janssen Pharmaceuticals Inc. Invega Trinza (paliperidone palmitate) extended-release injectable suspension, for intramuscular use: US prescribing information. 2016. Available from: http://www. janssencns. com/. Accessed April 30, 2017.

72. Gopal S, Vermeulen A, Nandy P, et al. Practical guidance for dosing and switching from paliperidone palmitate 1 monthly to 3 monthly formulation in schizophrenia. Curr Med Res Opin. 2015;31(11):2043-2054.

73. Gilday E, Nasrallah HA. Clinical pharmacology of paliperidone palmitate a parenteral long-acting formulation for the treatment of schizophrenia. Rev Recent Clin Trials. 2012;7(1):2-9.

74. Karlsson P, Hargarter L, Dencker E, et al. Pharmacokinetics and dopamine $\mathrm{d} 2$ and serotonin 5-HT2A receptor occupancy of paliperidone in healthy subjects: two open-label, single-dose studies (PAL-115). Pharmacopsychiatry. 2007;40(5):A106.

75. Remington G, Mamo D, Labelle A, et al. A PET study evaluating dopamine D2 receptor occupancy for long-acting injectable risperidone. Am J Psychiatry. 2006;163(3):396-401.

76. Nasrallah HA. Atypical antipsychotic-induced metabolite side effects: insights from receptor-binding profiles. Mol Psychiatry. 2008;13(1): 27-35.

77. Rodríguez FZ, Vega CB, Hernández MS, Macías JG, Leal FV. Use of paliperidone palmitate throughout a schizoaffective disorder patient's gestation period. Pharmacopsychiatry. 2017;50(1):38-40.
78. Ízdemir AK, Pak ŞC, Canan F, Gešici Í, Kuloğlu M, GŘcer MK. Paliperidone palmitate use in pregnancy in a woman with schizophrenia. Arch Womens Ment Health. 2015;18(5):739-740.

79. Ostuzzi G, Papola D, Gastaldon C, Barbui C. New EMA report on paliperidone 3-month injections: taking clinical and policy decisions without an adequate evidence base. Epidemiol Psychiatr Sci. 2017;26(3): 231-233.

80. European Medicines Agency, Committee for Medicinal Products for Human Use (2012). Guideline on Clinical Investigation of Medicinal Products, Including Depot Preparations in the Treatment of Schizophrenia. EMA/CHMP/40072/2010 Rev. 1. 2012. Available from: http:/www. ema.europa.eu/docs/en_GB/document_library/Scientific_guideline/ 2012/10/WC500133437.pdf. Accessed April 30, 2017.

81. Einarson TR, Bereza BG, Garcia Llinares I, González Martín Moro B, Tedouri F, Van Impe K. Cost-effectiveness of 3-month paliperidone treatment for chronic schizophrenia in Spain. J Med Econ. 2017; 20(10):1039-1047.

82. Einarson TR, Bereza BG, Tedouri F, Van Impe K, Denee TR, Dries PJ. Cost-effectiveness of 3-month paliperidone therapy for chronic schizophrenia in the Netherlands. J Med Econ. 2017;20(11): 1187-1199.

83. European Medicine Agency. Summary of product characteristics. Available from: http://www.ema.europa.eu/docs/en_GB/document_ library/EPAR_-_Product_Information/human/004066/WC500180640. pdf. Accessed October 30, 2017.
Neuropsychiatric Disease and Treatment

\section{Publish your work in this journal}

Neuropsychiatric Disease and Treatment is an international, peerreviewed journal of clinical therapeutics and pharmacology focusing on concise rapid reporting of clinical or pre-clinical studies on a range of neuropsychiatric and neurological disorders. This journal is indexed on PubMed Central, the 'PsycINFO' database and CAS,

\section{Dovepress}

and is the official journal of The International Neuropsychiatric Association (INA). The manuscript management system is completely online and includes a very quick and fair peer-review system, which is all easy to use. Visit http://www.dovepress.com/testimonials.php to read real quotes from published authors. 